\begin{tabular}{|c|c|}
\hline Title: & $\begin{array}{l}\text { Predictive Current Control and Online Parameter Identification of Interior Permanent } \\
\text { Magnet Synchronous Machines }\end{array}$ \\
\hline Authors: & Simon Decker, Jan Richter, Michael Braun \\
\hline Institute: & $\begin{array}{l}\text { Karlsruhe Institute of Technology (KIT) } \\
\text { Elektrotechnisches Institut (ETI) }\end{array}$ \\
\hline Type: & Conference Proceedings \\
\hline Published at: & $\begin{array}{l}\text { Proceedings } 2016 \text { European Conference on Power Electronics and Applications (EPE'16 } \\
\text { ECCE Europe), Karlsruhe, Germany, } 2016 \\
\text { Publisher: IEEE } \\
\text { Year: } 2016 \\
\text { ISBN: } 978-9-0758-1524-5\end{array}$ \\
\hline Hyperlinks: & DOI: $10.1109 / E P E .2016 .7695686$ \\
\hline
\end{tabular}

(C) 2016 IEEE. Personal use of this material is permitted. Permission from IEEE must be obtained for all other uses, in any current or future media, including reprinting/republishing this material for advertising or promotional purposes, creating new collective works, for resale or redistribution to servers or lists, or reuse of any copyrighted component of this work in other works. 


\title{
Predictive Current Control and Online Parameter Identification of Interior Permanent Magnet Synchronous Machines
}

\author{
Simon Decker, Jan Richter and Michael Braun \\ Karlsruhe Institute of Technology (KIT) \\ Kaiserstr. 12 \\ 76131, Karlsruhe \\ Phone: +4972160846857 \\ Email: simon.decker@kit.edu \\ URL: http://www.eti.kit.edu
}

\section{Keywords}

$\ll$ High performance drives», «Motion control, robotics, special drives $\gg$.

\begin{abstract}
This paper presents an online parameter identification method for interior permanent magnet synchronous machines with nonlinear magnetics. Usually model based control schemes are used to ensure dynamic, stable and accurate control. These schemes contain machine models with offline measured parameters that are stored in lookup tables. Extensive offline parametrization can be avoided when parameters are obtained online during regular drive operation. The proposed online parameter identification method enables fast identification of differential inductances and flux linkages within the short duration of two control periods using manipulated reference currents. Thereby, online identification of the parameter lookup tables and self-commissioning of deadbeat controllers is possible.
\end{abstract}

\section{Introduction}

High performance interior permanent magnet synchronous machines (IPMSM) require low weight, small size and high power. This demands high utilization of the machine materials yielding nonlinear magnetics caused by iron and cross-saturation. The electromagnetic behavior of the machine has to be known to allow dynamic, stable and accurate control of these machines. Precise machine models with parameter lookup tables (LUT) are applied for that purpose $[1,2,3]$. The parameters are given by the flux linkages, the inductances and the stator resistance and have to be identified before control is possible. There are numerous identification methods, but in general all procedures can be categorized as offline or online methods [4].

Offline methods use an ohmmeter to measure the stator resistance and either locked-rotor or steadystate tests to identify nonlinear magnetics $[5,6]$. However, a test-bench is required and manufacturing tolerances as well as parameter variations during drive operation are neglected. Online identification methods offer improvements because they continuously track all parameters. In the following, only methods that identify the stator resistance as well as the flux linkages and inductances are considered. The rotor angle is assumed to be measured by an encoder. Several methods of online identification were developed which rely on different principles. In general, methods with and without test signals can be distinguished.

Methods without test signals use the measured or estimated currents, voltages and the encoder angle and speed as inputs. The parameters are then directly calculated. In [8] the measured currents of the motor and two recursive least square algorithms (RLS), in combination with simplified machine equations are applied. Convergence of the RLS algorithm is achieved within ten control periods under all operational 
conditions. Faster convergence is possible with model reference adaptive systems, by tuning the adaptive system based on the machine equations. However, identification at low speed and the initialization at startup remains difficult [9]. A combination of a current model at low speed and a voltage model at high speed yields improvements [11]. Though, identifying the flux linkages by integration of the differential inductances results in integration errors.

Methods with test signals are less disturbance-sensitive because they specifically excite the machine with a known test signal. Different test signals are applied: alternating or sinusoidal voltages and currents as well as torque oscillations and speed ramps. Measurement and evaluation of the machine response yields the parameters. Voltage pulses were applied and the current deviation was evaluated to determine differential inductances during steady-state operation with a fundamental small signal model based on the machine equations [10]. Tracking during transient operation was achieved by using sinusoidal currents and discrete Fourier transformation of the measured currents to calculate the differential inductances. The permanent magnet flux linkage and stator resistance is identified by a RLS algorithm, the current depending flux linkages by a Gopinath observer structure. Due to the necessary Fourier transformation of the sinusoidal test signal, the differential inductances can identified only after a full cycle of the test signal for which $500 \mathrm{~Hz}$ were used [12]. Self commissioning methods avoid these problems by applying the test signals at standstill or startup of the control. A free turning rotor during acceleration and deceleration was used to calculate the flux linkages via the back electromotive force and simplified machine equations. The stator resistance was offline identified [14]. Identification at standstill is also possible when the rotor cannot turn freely. Fast torque oscillations at standstill and integration of the identified differential inductances yield the flux linkages [13]. Another approach is the identification using dc biased sinusoidal currents. The differential inductances were derived from a small signal model and integration of these yield the flux linkages [7].

In this paper an online identification and control method with test signals during regular drive operation is presented. The method operates under all operational conditions and enables fast identification of differential inductances and flux linkages within the short duration of two control periods by using manipulated reference currents. The method is based on simplified machine equations taking iron and cross-saturation into account. To cope with nonlinear magnetics the reference currents are dynamically manipulated to ensure small signal behavior. Then, extensive offline parametrization is not needed and all parameters required for deadbeat control can be obtained online during regular drive operation.

\section{Machine model}

A model of interior permanent magnet synchronous machines is derived in the following. Since these machines are magnetically anisotropic the machine model is described in the rotor-orientated dq-reference frame. Three symmetric, star-connected stator windings are assumed. The neutral-point of the machine is not attached to the inverter. As a result, current-, flux- and voltage-zero-components disappear. Friction losses as well as iron losses are neglected because of their small impact on machine control. Furthermore, dielectric currents, skin and proximity effects are not considered.

\section{Time continuous model}

The stator voltage equations are derived from Ohm 's law, Kirchhoff's law and the equations of Maxwell. The transformation from the stator-oriented three phase system to the rotor-oriented dq-reference frame yields:

$$
\begin{aligned}
& v_{\mathrm{d}}=R i_{\mathrm{d}}+L_{\mathrm{dd}} \frac{\mathrm{d} i_{\mathrm{d}}}{\mathrm{d} t}+L_{\mathrm{dq}} \frac{\mathrm{d} i_{\mathrm{q}}}{\mathrm{d} t}-\omega \psi_{\mathrm{q}} \\
& v_{\mathrm{q}}=R i_{\mathrm{q}}+L_{\mathrm{qq}} \frac{\mathrm{d} i_{\mathrm{q}}}{\mathrm{d} t}+L_{\mathrm{qd}} \frac{\mathrm{d} i_{\mathrm{d}}}{\mathrm{d} t}+\omega \psi_{\mathrm{d}}
\end{aligned}
$$

The ohmic resistance of the stator windings is $R$ and the electric angular frequency is $\omega$. Voltage, flux linkage and current components of the direct and quadrature axis are $v_{x}, \psi_{x}$ and $i_{x}$ with $x \in\{\mathrm{d}, \mathrm{q}\}$. Differential inductances $L_{x x}$ are partial derivatives of $\psi_{x}$ and occur due to the time differentiation of the flux linkages. Thereby $L_{\mathrm{dd}}, L_{\mathrm{qq}}$ denote the self inductance of the direct and quadrature axis and $L_{\mathrm{dq}}, L_{\mathrm{qd}}$ 
the cross-saturation inductances. Differential inductances and the flux linkages depend nonlinearly on the currents of both the direct and quadrature axis to account for iron and cross-saturation. In the following, the cross-saturation inductances are neglected. This is possible because the cross-saturation inductances $L_{\mathrm{dq}}, L_{\mathrm{qd}}$ are a lot smaller than the self-inductances $L_{\mathrm{dd}}, L_{\mathrm{qq}}$ in IPMSMs. For the machine under test they are at least five times smaller in the typical operational area [2].

\section{Time discrete model}

Modern control algorithms are implemented on microprocessors. Thus, (1) and (2) have to be discretized over time. Therefore, the trapezoidal rule is used requiring further approximations [2]. Firstly, the electric angular frequency $\omega$ is assumed to be constant for the duration $T_{\mathrm{C}}$ of one control period from $t_{n}$ to $t_{n+1}$. This is permitted when the inertia of the machine is sufficiently large which is the case for typical machines. Secondly, the flux linkages and currents are assumed to be stepwise linear during the control period. This yields a small signal model, as already presented $[7,10]$. Then, the stator voltages can be expressed with (3) and (4).

$$
\begin{aligned}
& v_{\mathrm{d}, t_{n}, t_{n+1}}=\frac{R}{2}\left(i_{\mathrm{d}, t_{n}}+i_{\mathrm{d}, t_{n+1}}\right)+L_{\mathrm{dd}} \frac{\left(i_{\mathrm{d}, t_{n+1}}-i_{\mathrm{d}, t_{n}}\right)}{T_{\mathrm{C}}}-\omega\left(\psi_{\mathrm{q}, t_{n}}+\frac{L_{\mathrm{qq}}}{2}\left(i_{\mathrm{q}, t_{n+1}}-i_{\mathrm{q}, t_{n}}\right)\right) \\
& v_{\mathrm{q}, t_{n}, t_{n+1}}=\frac{R}{2}\left(i_{\mathrm{q}, t_{n}}+i_{\mathrm{q}, t_{n+1}}\right)+L_{\mathrm{qq}} \frac{\left(i_{\mathrm{q}, t_{n+1}}-i_{\mathrm{q}, t_{n}}\right)}{T_{\mathrm{C}}}+\omega\left(\psi_{\mathrm{d}, t_{n}}+\frac{L_{\mathrm{dd}}}{2}\left(i_{\mathrm{d}, t_{n+1}}-i_{\mathrm{d}, t_{n}}\right)\right)
\end{aligned}
$$

\section{Identification}

The simplified time-discrete machine equations (3) and (4) are used to identify the unknown model parameters given by the stator resistance $R$, the flux linkages $\psi_{\mathrm{d}, t_{n}}$ and $\psi_{\mathrm{q}, t_{n}}$ as well as the differential inductances $L_{\mathrm{dd}}$ and $L_{\mathrm{qq}}$.

\section{Stator resistance}

The stator resistance $R$ can be repeatedly determined at standstill of the machine using constant currents. Then, the stator voltages are solely caused by the ohmic voltage drop and the stator resistance can be calculated by solving (3) or (4) simply using Ohm's law. For that purpose the measured currents and the voltage references of the voltage source inverter (VSI) are used. For stator resistance identification, only a direct current test signal is applied so that the machine does not generate torque. Since ohmic voltage drops are typically small in comparison to the machine nominal voltage, stator resistance identification errors are of minor importance. The integral term of the controller can easily cope with these small model errors.

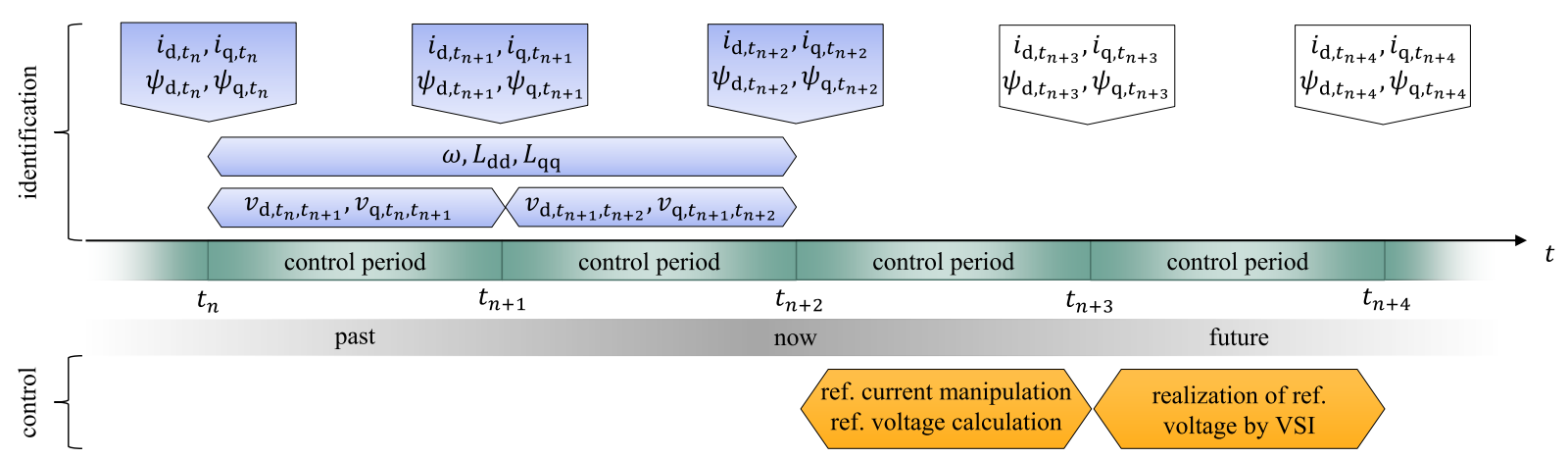

Fig. 1: Timing diagram of the online identification and control method. Identification is conducted using values of the past two control periods as given in blue. Current control functions are depicted in orange and consist of the manipulation of the reference currents and the reference voltage calculation. Due to the dead-time of the digital controller the voltage reference is realized one control period later by the VSI. 


\section{Flux linkages and differential inductances}

The already identified stator resistance $R$, the encoder rotor angle $\gamma$ and electric angular frequency $\omega$, the measured currents $i$ and the voltage references of the VSI $v$ are used for the identification of the flux linkages and differential inductances using (3) and (4). This is not trivial because identification depends on operational conditions. In general, three cases can be distinguished that have to be addressed separately:

1. Standstill or low speed: The back electromotive force is too low to be evaluated. As a consequence, the differential inductances can be identified when the currents change. The change of the currents has to be big enough to be observed but not too big so that magnetics are approximately linear within the control period that is used for identification. Flux linkages however, are not observable. Calculations are simple because (3) and (4) can be solved for the differential inductances with all required quantities being known.

$$
\begin{gathered}
L_{\mathrm{dd}}=\frac{T_{\mathrm{C}}}{\left(i_{\mathrm{d}, t_{n+2}}-i_{\mathrm{d}, t_{n+1}}\right)}\left(v_{\mathrm{d}, t_{n+1}, t_{n+2}}-\frac{R}{2}\left(i_{\mathrm{d}, t_{n+1}}+i_{\mathrm{d}, t_{n+2}}\right)\right) \\
L_{\mathrm{qq}}=\frac{T_{\mathrm{C}}}{\left(i_{\mathrm{q}, t_{n+2}}-i_{\mathrm{q}, t_{n+1}}\right)}\left(v_{\mathrm{q}, t_{n+1}, t_{n+2}}-\frac{R}{2}\left(i_{\mathrm{q}, t_{n+1}}+i_{\mathrm{q}, t_{n+2}}\right)\right)
\end{gathered}
$$

2. High speed and stationary operation: The currents are constant, so $i_{x, t_{n+1}}=i_{x, t_{n+2}}$ with $x \in\{\mathrm{d}, \mathrm{q}\}$. Thus, the induced voltages caused by current changes disappear and only the flux linkages can be identified. The differential inductances cannot be observed. Again, calculations are rather easy because (3) and (4) can be solved for the flux linkages with all other quantities being known.

$$
\begin{aligned}
& \psi_{\mathrm{d}, t_{n+1}}=\frac{1}{\omega}\left(v_{\mathrm{q}, t_{n+1}, t_{n+2}}-R i_{\mathrm{q}, t_{n+1}}\right) \\
& \psi_{\mathrm{q}, t_{n+1}}=-\frac{1}{\omega}\left(v_{\mathrm{d}, t_{n+1}, t_{n+2}}-R i_{\mathrm{d}, t_{n+1}}\right)
\end{aligned}
$$

3. High speed and dynamic operation: This is the most general case when the machine currents change while the rotor turns. Thus, stator voltage components occur due to the ohmic resistance, the changing current and the back electromotive force. Identification within a single control period is not possible because these voltage drops cannot be separated as (3) and (4) are an under-determined linear system of two equations with four parameters $L_{\mathrm{dd}}, L_{\mathrm{qq}}, \psi_{\mathrm{d}, t_{n}}, \psi_{\mathrm{q}, t_{n}}$ being unknown. A possible solution is described in the following. It allows precise and fast online identification of differential inductances and flux linkages during dynamic operation.

When the dynamic change of the currents is not too large for the duration of two control periods, the differential inductances can be assumed to be identical for that length of time as indicated in Fig. 1. Then, (3) and (4) can be set up for two control periods yielding a linear system of four equations with four parameters being unknown.

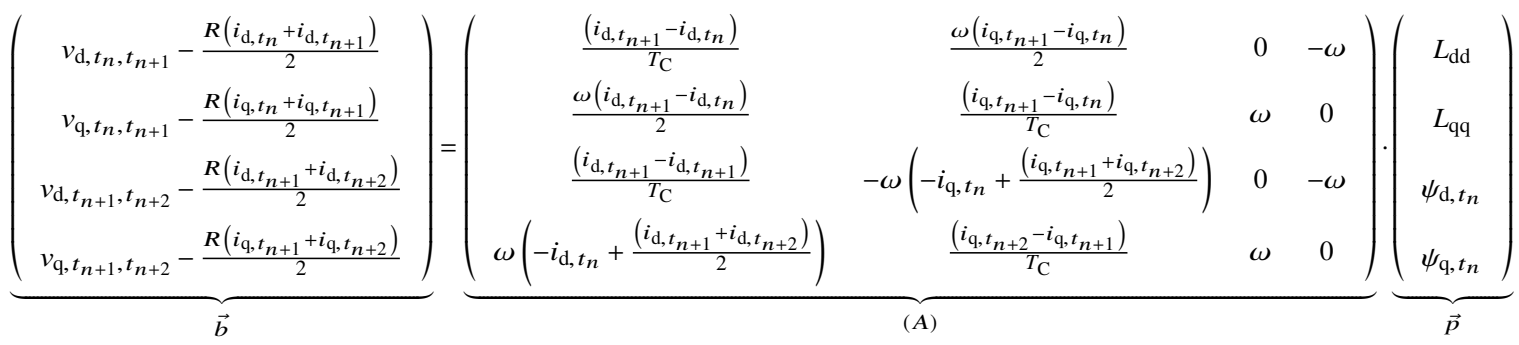

The linear system of equations can be written as $\vec{b}=(A) \cdot \vec{p}$. The matrix $(A)$ and the vector $\vec{b}$ consist of known or measured quantities and the vector $\vec{p}$ contains the unknown parameters. To solve the linear system of equations for the vector $\vec{p}$, the matrix $(A)$ has to be inverted. This is only possible if the 
determinant of the matrix $(A)$ is not equal to zero. With the assumption that $T_{\mathrm{C}}<<\frac{1}{\omega}$ which is valid for typical VSI switching frequencies and electric angular frequencies of IPMSMs, the determinant is:

$$
\operatorname{det}(A) \approx \omega^{4}\left(\frac{\left(\left(i_{\mathrm{q}, t_{n+1}}-i_{\mathrm{q}, t_{n}}\right)-\left(i_{\mathrm{q}, t_{n+2}}-i_{\mathrm{q}, t_{n+1}}\right)\right)\left(\left(i_{\mathrm{d}, t_{n+1}}-i_{\mathrm{d}, t_{n}}\right)-\left(i_{\mathrm{d}, t_{n+2}}-i_{\mathrm{d}, t_{n+1}}\right)\right)}{T_{\mathrm{C}}^{2} \omega^{2}}\right)
$$

It is apparent that the calculation of $\vec{p}$ is only possible under certain constraints. Firstly, the electrical angular frequency $\omega$ has to be nonzero which is always true in the third case. Secondly, the current has to change differently in the two control periods in both axis. Under these conditions, the explicit solution of the linear system of equations is possible and can be easily executed on microprocessors. The validity of the used assumption (small signal model valid, different current changes) has to be ensured by the control algorithm by respective manipulation of the reference currents.

\section{Control}

The control scheme including online identification for filling the LUTs in combination with the predictive control scheme is displayed in Fig. 2. All shown functions are executed repeatedly in every control period. The identification method of the stator resistance, the differential inductances and the flux linkages are described in the previous section and shown in the middle of the left side of the graph. The identification results of the flux linkages are stored in LUTs. When the LUTs are filled, the data is used in a predictive trajectory controller realizing optimal deadbeat control [15] as shown on the bottom on the left side. This is out of the scope of this paper and not covered in the following. When the LUTs are not filled a control method is applied that uses the online identified parameters as depicted on the top of the left side. It consists of two parts: The manipulation of the reference currents to enable online parameter identification and the calculation of the VSI reference voltages. These two functions are described in detail in the following.

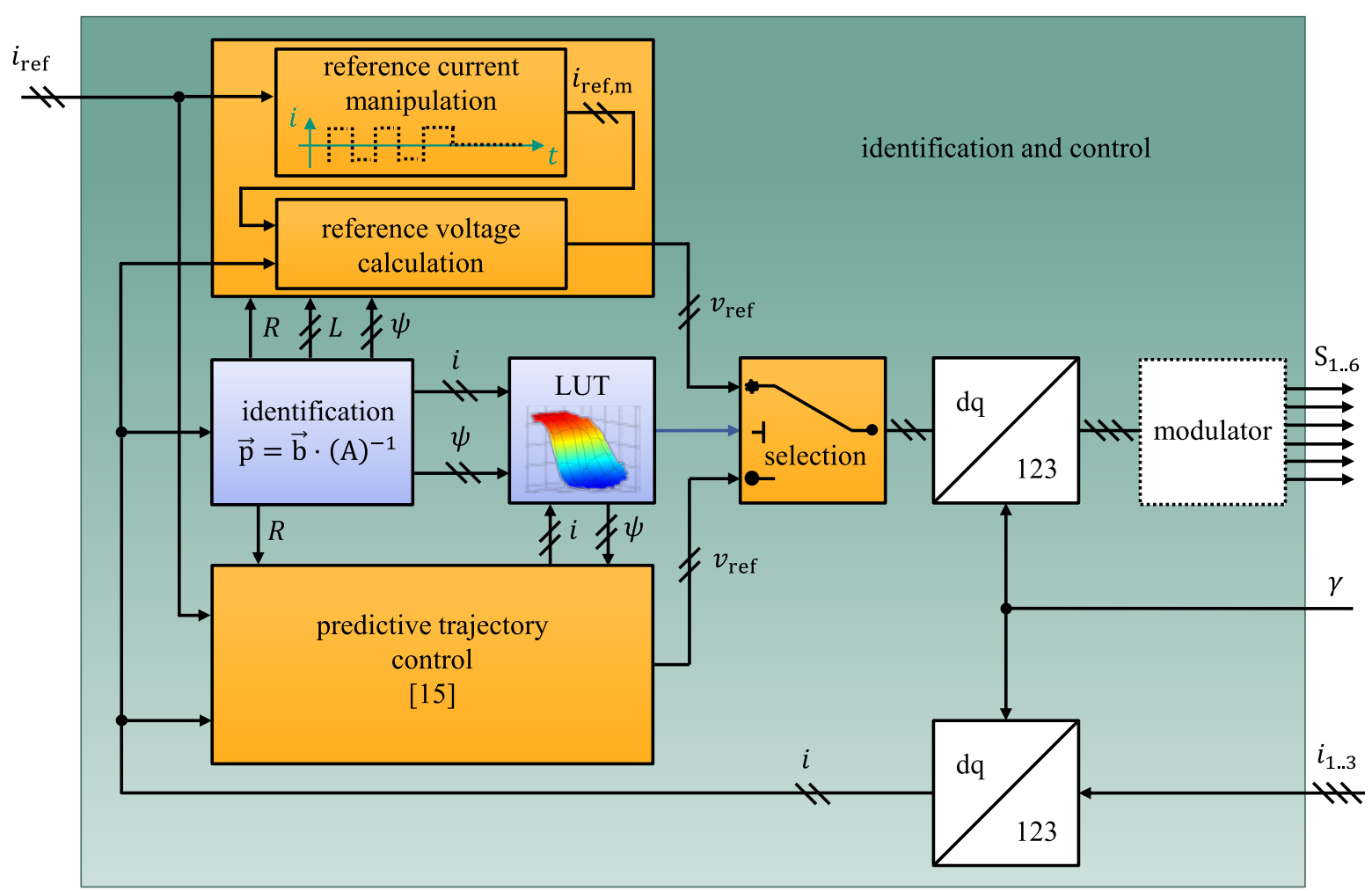

Fig. 2: Block diagram of the online identification and control method. The inputs are the reference and measured currents as well as the encoder rotor angle and speed. The outputs are the gate signals of the modulator that are fed to the VSI as shown in Fig. 4. 


\section{Reference current manipulation}

The reference currents of the current controller are assumed to be known and e.g. directly provided by a superposed speed or position controller. To enable online identification of all parameters the reference currents have to be manipulated. Reference current manipulation depends on the operational conditions as defined by the three cases in the section 'Flux linkages and differential inductances'.

1. Standstill or low speed: When the stator resistance is to be determined, a constant direct axis reference current is set to allow resistance identification. Reference currents are approached by small, unequal back and forth current ripples. This allows differential inductance identification. When the reference currents are reached the current ripple is switched off because differential inductances are constant and consequently do not have to be identified.

2. High speed and stationary operation: In this case the reference currents are not manipulated. Identification of the flux linkages is directly possible.

3. High speed and dynamic operation: Reference currents are also approached by small, unequal back and forth current ripples as visible in Fig. 5. This allows flux linkage and differential inductance identification. When the reference currents are reached, the current ripple is switched off because all parameters are constant and thus do not have to be identified.

The manipulated reference currents are used to calculate the current control deviation and the reference voltage of the VSI afterwards.

\section{Reference voltage calculation}

The calculation time of the microprocessor introduces a dead-time that has to be compensated. This is done by current prediction. The currents are predicted to $t_{n+3}$ from the measured currents at $t_{n+2}$, using the VSI reference voltage active in the control period from $t_{n+2}$ to $t_{n+3}$ and the previously online identified parameters. Therefore, (3) and (4) are set up for the control period from $t_{n+2}$ to $t_{n+3}$ with the flux linkages $\psi_{\mathrm{d}, t_{n+2}}$ and $\psi_{\mathrm{q}, t_{n+2}}$ being calculated using the online identified flux linkages, differential inductances and measured currents.

$$
\begin{aligned}
& v_{\mathrm{d}, t_{n+2}, t_{n+3}}=\frac{R}{2}\left(i_{\mathrm{d}, t_{n+2}}+i_{\mathrm{d}, t_{n+3}}\right)+L_{\mathrm{dd}} \frac{\left(i_{\mathrm{d}, t_{n+3}}-i_{\mathrm{d}, t_{n+2}}\right)}{T_{\mathrm{C}}}-\omega\left(\psi_{\mathrm{q}, t_{n+2}}+\frac{L_{\mathrm{qq}}}{2}\left(i_{\mathrm{q}, t_{n+3}}-i_{\mathrm{q}, t_{n+2}}\right)\right) \\
& v_{\mathrm{q}, t_{n+2}, t_{n+3}}=\frac{R}{2}\left(i_{\mathrm{q}, t_{n+2}}+i_{\mathrm{q}, t_{n+3}}\right)+L_{\mathrm{qq}} \frac{\left(i_{\mathrm{q}, t_{n+3}}-i_{\mathrm{q}, t_{n+2}}\right)}{T_{\mathrm{C}}}+\omega\left(\psi_{\mathrm{d}, t_{n+2}}+\frac{L_{\mathrm{dd}}}{2}\left(i_{\mathrm{d}, t_{n+3}}-i_{\mathrm{d}, t_{n+2}}\right)\right)
\end{aligned}
$$

Equations (11) and (12) can be solved for the predicted currents $i_{\mathrm{d}, t_{n+3}}$ and $i_{\mathrm{q}, t_{n+3}}$. Using the manipulated reference currents $i_{\mathrm{d}, \text { ref,m, } t_{n+2}}$ and $i_{\mathrm{q}, \mathrm{ref}, \mathrm{m}, t_{n+2}}$, the predicted currents and (3) and (4) in the control period from $t_{n+3}$ to $t_{n+4}$ the next VSI reference voltages $v_{\mathrm{d}}^{*}$ and $v_{\mathrm{q}}^{*}$ can be calculated. The predicted flux linkages $\psi_{\mathrm{d}, t_{n+3}}$ and $\psi_{\mathrm{q}, t_{n+3}}$ are therein obtained from the online identified flux linkages, differential inductances and predicted currents.

$$
\begin{aligned}
& v_{\mathrm{d}}^{*}=\frac{R}{2}\left(i_{\mathrm{d}, t_{n+3}}+i_{\mathrm{d}, \mathrm{ref}, \mathrm{m}, t_{n+2}}\right)+L_{\mathrm{dd}} \frac{\left(i_{\mathrm{d}, \mathrm{ref}, \mathrm{m}, t_{n+2}}-i_{\mathrm{d}, t_{n+3}}\right)}{T_{\mathrm{C}}}-\omega\left(\psi_{\mathrm{q}, t_{n+3}}+\frac{L_{\mathrm{qq}}}{2}\left(i_{\mathrm{q}, \mathrm{ref}, \mathrm{m}, t_{n+2}}-i_{\mathrm{q}, t_{n+3}}\right)\right) \\
& v_{\mathrm{q}}^{*}=\frac{R}{2}\left(i_{\mathrm{q}, t_{n+3}}+i_{\mathrm{q}, \mathrm{ref}, \mathrm{m}, t_{n+2}}\right)+L_{\mathrm{qq}} \frac{\left(i_{\mathrm{q}, \mathrm{ref}, \mathrm{m}, t_{n+2}}-i_{\mathrm{q}, t_{n+3}}\right)}{T_{\mathrm{C}}}+\omega\left(\psi_{\mathrm{d}, t_{n+3}}+\frac{L_{\mathrm{dd}}}{2}\left(i_{\mathrm{d}, \mathrm{re}, \mathrm{m}, t_{n+2}}-i_{\mathrm{d}, t_{n+3}}\right)\right)
\end{aligned}
$$

To achieve stationary accuracy an integral term is added as shown in Fig. 3. The inputs of the integral term are the manipulated reference currents $i_{\mathrm{d}, \mathrm{ref}, \mathrm{m}, t_{n}}$ and $i_{\mathrm{q}, \mathrm{ref}, \mathrm{m}, t_{n}}$, the measured currents and the previously calculated integral parts $\Delta v_{\mathrm{d}, \text { int }, t_{n+2}, t_{n+3}}$ and $\Delta v_{\mathrm{q}, \text { int }, t_{n+2}, t_{n+3}}$. The integral parts are calculated using (15) and (16) with $k_{i}$ as integral gain. 


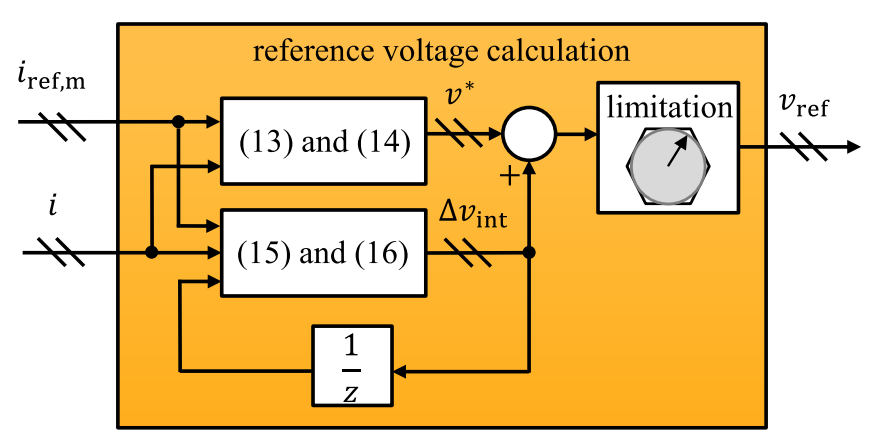

Fig. 3: Block diagram of the reference voltage calculation.

$$
\begin{aligned}
& \Delta v_{\mathrm{d}, \text { int }}=k_{i} \cdot \frac{L_{\mathrm{dd}}\left(i_{\mathrm{d}, \mathrm{ref}, \mathrm{m}, t_{n}}-i_{\mathrm{d}, t_{n+2}}\right)}{T_{\mathrm{C}}}+\Delta v_{\mathrm{d}, \text { int }, t_{n+2}, t_{n+3}} \\
& \Delta v_{\mathrm{q}, \text { int }}=k_{i} \cdot \frac{L_{\mathrm{qq}}\left(i_{\mathrm{q}, \text { ref }, \mathrm{m}, t_{n}}-i_{\mathrm{q}, t_{n+2}}\right)}{T_{\mathrm{C}}}+\Delta v_{\mathrm{q}, \text { int }, t_{n+2}, t_{n+3}}
\end{aligned}
$$

As a last step the calulated voltages are cropped to the inner circle of the inverter hexagon voltage limit due to the limited dc link voltage as shown in Fig. 3. This results in the VSI reference voltage $v_{\text {ref. }}$. If the inverter voltage limit is exceeded, the integral parts are hold constant as classic anti-windup strategy. For better readability this is not shown in Fig. 3 .

\section{Experimental setup}

The motor under test is an interior permanent magnet synchronous machine of type Brusa HSM16.1712-CO1 used for automotive traction applications. The load machine is an induction machine (IM) by Wittur. The voltage source inverters for grid connection and control of both machines are connected as indicated in Fig. 4. Modules of type Semikron SkiiP 513GD122-3DUL with a switching and controlling frequency of $8 \mathrm{kHz}$ are used. The currents are measured by the internal transducers of the SkiiP modules. The speed and the rotor angle are detected with the machines internal 14 bit encoders. The measured values are sampled with $8 \mathrm{kHz}$. Parameter identification and control are implemented on the TMS320C6748 digital signal processor from

Table I: Brusa HSM1-6.1712-CO1

\begin{tabular}{ccc}
\hline characteristics & & values \\
\hline \hline voltage & nominal & $212 \mathrm{~V}$ \\
current & nominal & $169 \mathrm{~A}$ \\
& maximal & $300 \mathrm{~A}$ \\
speed & nominal & $4200 \mathrm{~min}^{-1}$ \\
& maximal & $11000 \mathrm{~min}^{-1}$ \\
shaft Power & nominal & $57 \mathrm{~kW}$ \\
& maximal & $97 \mathrm{~kW}$ \\
torque & nominal & $130 \mathrm{Nm}$ \\
& maximal & $220 \mathrm{Nm}$ \\
ohmic resistance & typical & $10.5 \mathrm{~m} \Omega$ \\
pole pairs & & 3 \\
\hline
\end{tabular}
Texas Instruments. The parameters are saved in the DSP internal cache. The inverter switching signals are generated by a modulator implemented on a Cyclone 4 field programmable gate array from Altera.

\section{Measurement results}

The identification and control method is exemplarily tested with the motor under test. Stator resistance identification is covered as well as dynamic operation for a step response of the quadrature current at $750 \mathrm{~min}^{-1}$. 


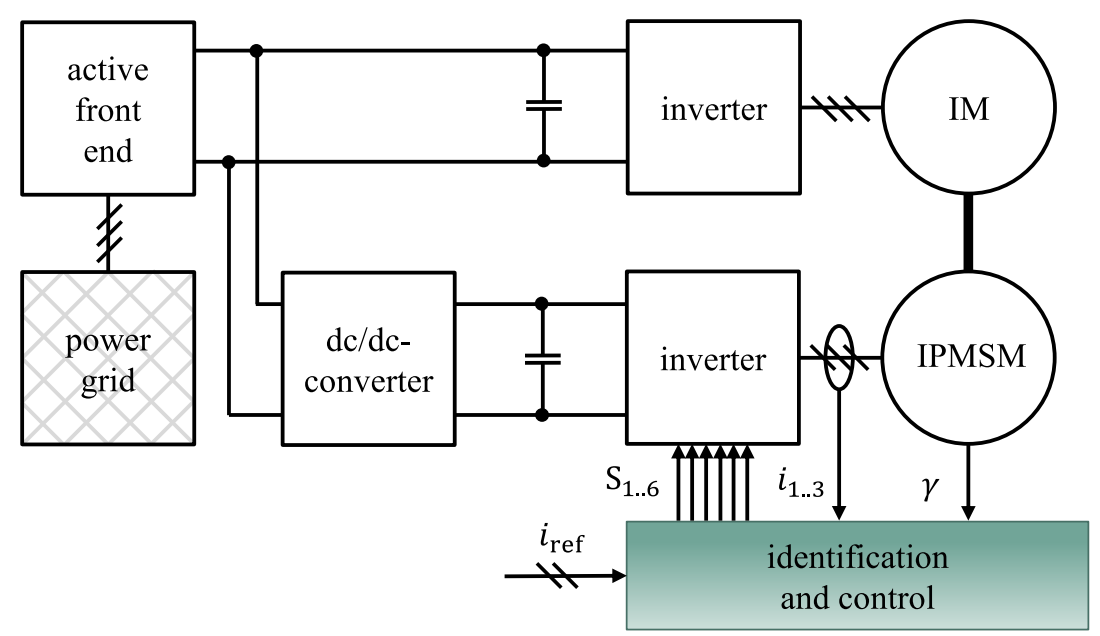

Fig. 4: Block diagram of the used test bench.

\section{Stator resistance}

Stator resistance identification is performed at motor standstill with direct current of $-200 \mathrm{~A}$. A value of $43 \mathrm{~m} \Omega$ is obtained. This is four times larger than the result given in Table I which is measured by an ohmmeter. The difference can be explained by the influences of additional contact and supply line resistances and inverter nonlinearities such as forward voltages, differential resistances and not perfectly compensated inverter dead-times. Because the total ohmic voltage drop is relevant for machine control, the online identified resistance should be used for machine control.

\section{Flux linkages and differential inductances}

The identification of the differential inductances is demonstrated for a step response of the quadrature current from $0 \mathrm{~A}$ to $300 \mathrm{~A}$ at constant direct current of $-100 \mathrm{~A}$ and constant speed of $750 \mathrm{~min}^{-1}$. Measurement results are given in the plots of Fig. 5. There, the blue lines depict the reference currents, black dots the measured current samples that are linearly connected by green lines for better readability. The quadrature current reference values is reached in $10 \mathrm{~ms}$. The predictive trajectory controller using offline measured flux linkage LUTs [15] only requires $1 \mathrm{~ms}$ for the same quadrature current step. Though, after the current step was slowly executed once with the flux linkages being identified online and stored in the LUTs, the reference voltage calculation can be switched to the predictive trajectory controller as indicated in Fig. 2. As a consequence high dynamic control is possible, although control is significantly slower when the flux linkages are unknown.
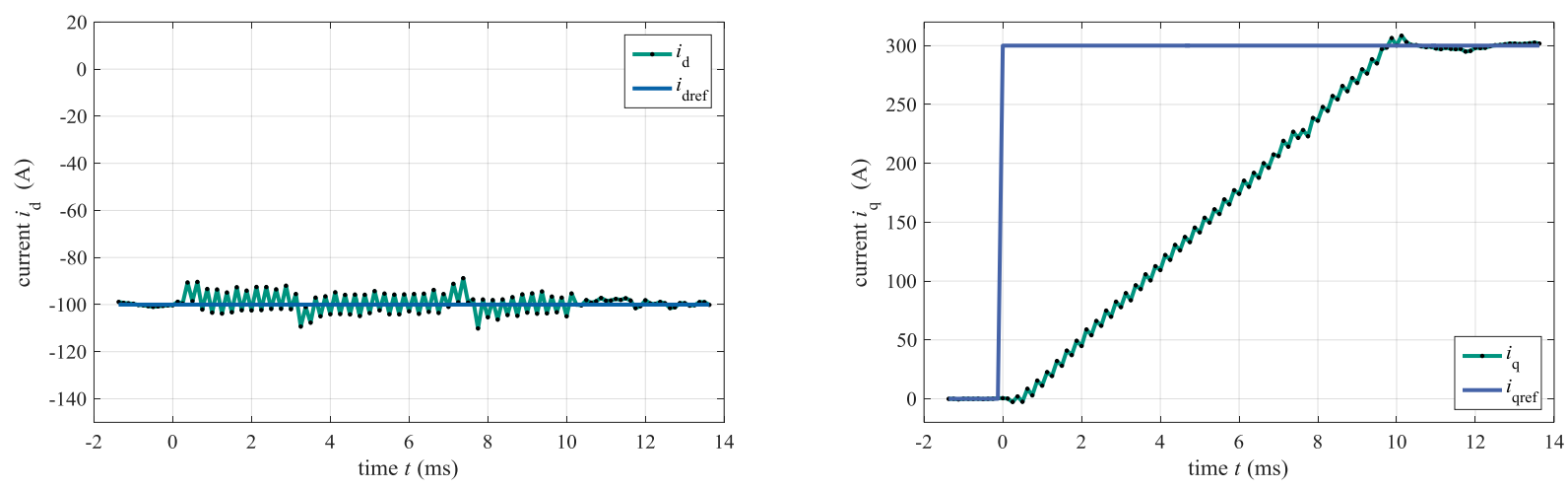

Fig. 5: Step response of the quadrature current of the described online identification and control method at a rotor speed of $750 \mathrm{~min}^{-1}$. 
(a)
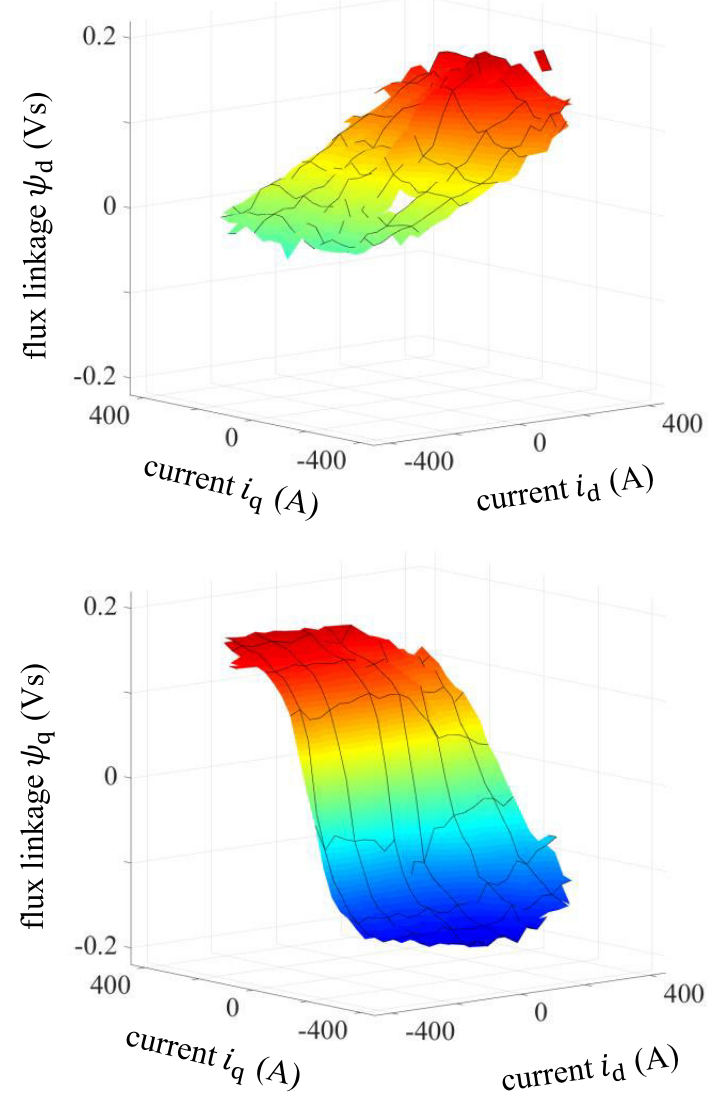

(b)
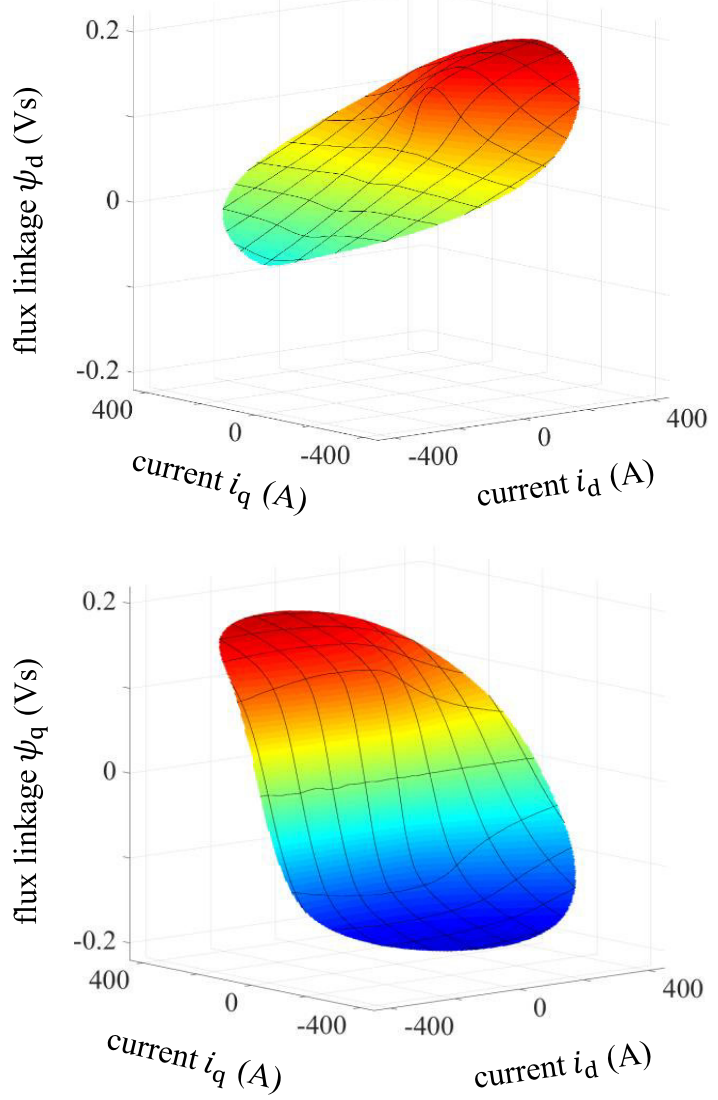

Fig. 6: Direct and quadrature flux linkages for the motor under test. In (a) the unfiltered flux linkages of a single online identification cycle of dynamic operation are shown. In (b) the flux linkages determined by offline steady-state measurements are depicted.

The online identified flux linkages are saved in the internal memory of the microprocessor as LUTs. After various current steps the LUTs are completely filled with online identified flux linkages. Identification results are shown in Fig. 6 (a). Flux linkages identified by offline steady-state measurements are displayed in Fig. 6 (b) for comparison. All plots have a circular boundary due to the maximal current limit of the machine. Nonlinear magnetics of both the online and offline identified flux linkages are clearly visible. The flux linkage $\psi_{\mathrm{d}}$ changes nonlinearly with $i_{\mathrm{d}}$ and $\psi_{\mathrm{q}}$ does with $i_{\mathrm{q}}$ due to iron saturation. Because of magnetic anisotropy the slope of $\psi_{\mathrm{q}}$ in $i_{\mathrm{q}}$-direction is steeper than the one of $\psi_{\mathrm{d}}$ in $i_{\mathrm{d}}$ direction. The graph of $\psi_{\mathrm{d}}$ is distorted in dependance on $i_{\mathrm{q}}$ and $\psi_{\mathrm{q}}$ on $i_{\mathrm{d}}$ because of cross-saturation. The online identified flux linkages contain noisy jittering because only online identification results of a single identification period during dynamic measurements are used (case 3.). Filtering of the online identified flux linkages can resolve this issue.

\section{Summary}

In this paper a control method is described that identifies the flux linkages and differential inductances online during regular drive operation. The influences of nonlinear magnetics caused by iron and crosssaturation are considered. The method is based on simplified voltage equations and test signal generation by reference current manipulation that allow flux linkage and differential inductance identification within the short duration of two control periods. First measurements with an automotive traction machine proof the concept and basic functionality. By saving the online identified flux linkages in lookup tables, the presented method can be used to commission dead-beat controllers during regular drive operation without the need of extensive offline measurements or startup self-commissioning. 


\section{References}

[1] J. Weigel and P. Mutschler, "Modelling and control of a permanent magnet linear synchronous motor featuring unbalance and saturation including cross-saturation," in Power Electronics Specialists Conference, Aachen, Germany, June 2004, pp. 2204-2210.

[2] J. Richter, T. Gemassmer and M. Doppelbauer, "Predictive current control of saturated cross-coupled permanent magnet synchronous machines," in Power Electronics, Electrical Drives, Automation and Motion, Ischia, Italy, June 2014, pp.830-835.

[3] J. S. Lee, C. H. Choi, J. K. Seok and R. D. Lorenz, "Deadbeat-direct torque and flux control of interior permanent magnet synchronous machines with discrete time stator current and stator flux linkage observer," IEEE Trans. on Ind. Appl., vol. 47, no. 4, pp. 1749-1758, July-Aug. 2011.

[4] S. A. Odhano, R. Bojoi, M. Popescu and A. Tenconi, "Parameter identification and self-commissioning of AC permanent magnet machines - a review," in IEEE Workshop on Electrical Machines Design, Control and Diagnosis, Torino, Italy, March 2015, pp.195-203.

[5] B. Stumberger, G. Stumberger, D. Dolinar, A. Hamler and M. Trlep, "Evaluation of saturation and crossmagnetization effects in interior permanent-magnet synchronous motor," IEEE Trans. on Ind. Appl., vol.39, no.5, pp.1264-1271, Sept.-Oct. 2003.

[6] J. Richter, A. Dollinger and M. Doppelbauer, "Iron loss and parameter measurement of permanent magnet synchronous machines," in International Conference on Electrical Machines, Berlin, Germany, Sept. 2014, pp.1635-1641.

[7] S. A. Odhano, R. Bojoi, S. G. Rosu and A. Tenconi, "Identification of the magnetic model of permanentmagnet synchronous machines using DC-biased low-frequency AC signal injection," IEEE Trans. on Ind. Appl., vol. 51, no. 4, pp. 3208-3215, July-Aug. 2015.

[8] S. J. Underwood and I. Husain, "Online parameter estimation and adaptive control of permanent-magnet synchronous machines," IEEE Trans. on Ind. Electron., vol. 57, no. 7, pp. 2435-2443, July 2010.

[9] G. Gatto, I. Marongiu and A. Serpi, "Discrete-time parameter identification of a surface-mounted permanent magnet synchronous machine," IEEE Trans. on Ind. Electron., vol.60, no.11, pp.4869-4880, Nov. 2013.

[10] F. De Belie, O. Ellabban, P. Lataire, K. Vandemergel and J. Melkebeek, "Identification of the synchronous machine inductances by using switching power converters applied in sensorless and current control," in 13th European Conference on Power Electronics and Applications, Barcelona, Spain, Sept. 2009, pp.1-11.

[11] G. Zanuso, L. Peretti and M. Zigliotto, "Permanent magnet synchronous machines flux linkage estimation with zero steady-state error and its field-programmable gate array implementation," IET Electric Power Applications, vol. 9, no. 4, pp. 332-343, April 2015.

[12] W. Xu and R. D. Lorenz, "High-frequency injection-based stator flux linkage and torque estimation for DBDTFC implementation on IPMSMs considering cross-saturation effects," IEEE Trans. on Ind. Appl., vol. 50, no. 6, pp. 3805-3815, Nov.-Dec. 2014.

[13] L. Peretti, P. Sandulescu and G. Zanuso, "Self-commissioning of flux linkage curves of synchronous reluctance machines in quasi-standstill condition," IET Electric Power Applications, vol. 9, no. 9, pp. 642-651, Nov. 2015.

[14] G. Pellegrino, B. Boazzo and T. M. Jahns, "Plug-in direct-flux vector control of PM synchronous machine drives," IEEE Trans. on Ind. Appl., vol. 51, no. 5, pp. 3848-3857, Sept.-Oct. 2015.

[15] J. Richter and M. Doppelbauer, "Predictive trajectory control of permanent-magnet synchronous machines with nonlinear magnetics," IEEE Trans. on Ind. Electron., vol. 63, no. 6, pp. 3915-3924, June 2016. 